\title{
Space-time clustering characteristics of dengue based on ecological, socio-economic and demographic factors in northern Sri Lanka
}

\author{
Sumiko Anno, ${ }^{1}$ Keiji Imaoka, ${ }^{2}$ Takeo Tadono, ${ }^{2}$ Tamotsu Igarashi, ${ }^{3}$ \\ Subramaniam Sivaganesh, ${ }^{4}$ Selvam Kannathasan, ${ }^{5}$ Vaithehi Kumaran, ${ }^{5}$ \\ Sinnathamby Noble Surendran ${ }^{5}$ \\ 1Shibaura Institute of Technology, Tokyo; 2 Japan Aerospace Exploration Agency, Ibaraki; \\ ${ }^{3}$ Remote Sensing Technology Center of Japan, Tokyo, Japan; ${ }^{4}$ Regional Epidemiologist, \\ Jaffna; ${ }^{5}$ University of Jaffna, Jaffna, Sri Lanka
}

\begin{abstract}
The aim of the present study was to identify geographical areas and time periods of potential clusters of dengue cases based on ecological, socio-economic and demographic factors in northern Sri Lanka from January 2010 to December 2013. Remote sensing (RS) was used to develop an index comprising rainfall, humidity and temperature data. Remote sensing data gathered by the AVNIR-2 instrument onboard the ALOS satellite were used to detect urbanisation, and a digital land cover map was used to extract land cover information. Other data on relevant factors and dengue outbreaks were collected through institutions and extant databases. The analysed RS data and databases were integrated into a geographical information system (GIS) enabling space-time clustering analysis. Our results indicate that increases in
\end{abstract}

Correspondence: Sumiko Anno, Shibaura Institute of Technology, 3-7-5 Toyosu, Koto-ku, Tokyo, 135-8548 Japan.

Tel: +81.3.5859.8363 - Fax: +81.3.5859.8401.

E-mail: annou@sic.shibaura-it.ac.jp

Contributions: SA, data analysis and manuscript writing; KI, TT, TI, remotesensing data collection and analysis; SS, SK, VK, SNS, data collection.

Conflict of interest: the authors declare no potential conflict of interest.

Conference presentation: part of this paper was presented at the ICGIS 2015: 17th International Conference on Geographic Information Systems, May 1819, 2015, Paris, France.

Acknowledgments: the authors would like to thank the Japan Aerospace Exploration Agency for providing the datasets of ALOS.

Received for publication: 21 May 2015.

Revision received: 5 September 2015.

Accepted for publication: 16 October 2015.

CC Copyright S. Anno et al., 2015

Licensee PAGEPress, Italy

Geospatial Health 2015; 10:376

doi:10.4081/gh.2015.376

This article is distributed under the terms of the Creative Commons Attribution Noncommercial License (by-nc 3.0) which permits any noncommercial use, distribution, and reproduction in any medium, provided the original author(s) and source are credited. the number of combinations of ecological, socio-economic and demographic factors that are present or above the average contribute to significantly high rates of space-time dengue clusters. The spatio-temporal association that consolidates the two kinds of associations into one can ensure a more stable model for forecasting. An integrated spatiotemporal prediction model at a smaller level using ecological, socioeconomic and demographic factors could lead to substantial improvements in dengue control and prevention by allocating the right resources to the appropriate places at the right time.

\section{Introduction}

Dengue is a vector-borne viral disease transmitted by Aedes mosquitoes, which has substantially increased relatively recently threatening a very large number of the world's population, mainly in the tropics (WHO, 2011). Dengue remains a major and growing public health problem in Sri Lanka with a rate of 220 per 100,000 people, and approximately a quarter of notified cases occur in children under 15 years living in dengue transmission areas (Tam et al., 2013). The disease is a common cause of childhood fever in this country, which has a history of over 40 years of dengue and has experienced a number of large epidemics in the past decade. Indeed, progressively larger epidemics have occurred at regular intervals since the early 2000 s.

Dengue transmission shows significant variations in time and space (Kanakaratne, 2009; WHO, 2011; Tam et al., 2013), and outbreaks are affected by ecological, socio-economic and demographic factors that also vary over time and space. Disease-promoting factors include: i) climate, such as rainfall, humidity and temperature (Canyon, 1999); ii) changes in land cover, particularly rapid unplanned expansion of urbanisation with inadequate housing and infrastructure (Gubler, 1997; Rodhain and Rosen, 1997; Lian et al., 2006; 0oi and Gubler, 2008; Tran et al., 2010; Gubler, 2011; WHO, 2012); iii) transportation networks (Sharma et al., 2014); and iv) high population density (Gubler, 1998).

Humidity supports Aedes fecundity, while rainfall fills natural and artificial containers, creating breeding sites for the dengue vector. Increasing temperature impacts virus development as well as vector survival, leading to increases in the proportion of infectious vectors, mosquito dispersion and biting rates. Furthermore, when the time required for viral generation diminishes (as it does at higher temperatures and humidity), transmission is much more efficient than otherwise (Canyon, 1999).

Rapid unplanned expansion of urbanisation leads to the development of urban communities with inadequate housing and poor infra- 
structure, including water, sewage systems and waste management. The lack of adequate water supply in such urban areas necessitates water storage in large containers, such as clay jars and cisterns. Automobile tires and plastic containers in the crowded urban environment also create water reservoirs after rain (Lian et al., 2006; Ooi and Gubler, 2008; Tran et al., 2010; Gubler, 2011). These indoor/outdoor water storage containers are potential mosquito breeding sites. Aedes aegypti is a highly domesticated urban mosquito that preferentially lives in human homes, feeding on humans and laying eggs in humanmade containers (Gubler, 1997). It is an opportunistic breeder, highly adapted to urban and domestic environments (Rodhain and Rosen, 1997; WHO, 2012). Humans are hosts for the virus, and thus the likelihood of transmission increases with increased population density (Gubler, 1998). The increased global incidence of dengue is thus linked to rapid, unplanned urbanisation. A recent study demonstrated the first evidence for a dengue dispersal pattern in association with transportation hubs in space and time for Trinidad, West Indies (Sharma et al., 2014). In the absence of an effective vaccine and specific treatment, vector control is the only way to prevent dengue transmission (Banu et al., 2012). Detection methods for space-time clusters, signalled by a higher density of event occurrences in certain places at certain times, are dynamic techniques that are essential for the determination of when, where and to what degree a disease is present. Therefore, these approaches are useful for prioritising dengue surveillance and vector control (Dempsey et al., 2009; Solano et al., 2014). Although many studies have examined space-time clustering of dengue, the impact of socio-demographic changes and climatic factors on dengue transmission in clustered areas remains to be determined (Jeefoo et al., 2011; Banu et al., 2012).

Our study aim was to investigate the impact of ecological factors (i.e., rainfall, humidity, temperature and land cover, including rapid unplanned expansion of urbanisation) and socio-economic and demo- graphic factors (i.e., transportation network and population density) on space-time dengue clusters at the division level in northern Sri Lanka. We therefore identified the ecological, socio-economic and demographic characteristics of space-time clusters involving high rates of dengue cases. Such outbreaks in Sri Lanka are spatially heterogeneous, and investigating the spatial-temporal relationships between these various factors and dengue outbreaks at the local level is expected to help to better target surveillance and control.

\section{Materials and Methods}

\section{Study area}

Our study area was the northern region of Sri Lanka, consisting of 12 medical health offices ( $\mathrm{MOH})$, which are the health administrative divisions in Sri Lanka. Each MOH division has different geographical features, including agricultural fields, forested areas, wetlands, grassland, urban areas as well as different socio-economic and demographic backgrounds. The climate in the region is tropical with two monsoon seasons: the northeast monsoon from November to April and the southwest monsoon from May to October.

\section{Dengue data}

The monthly numbers of clinically confirmed dengue cases from January 2010 through December 2013 in the $12 \mathrm{MOH}$ divisions were obtained from these very divisions. The annual estimates of clinically confirmed dengue cases from 2007 through 2013 at the level were similarly obtained.

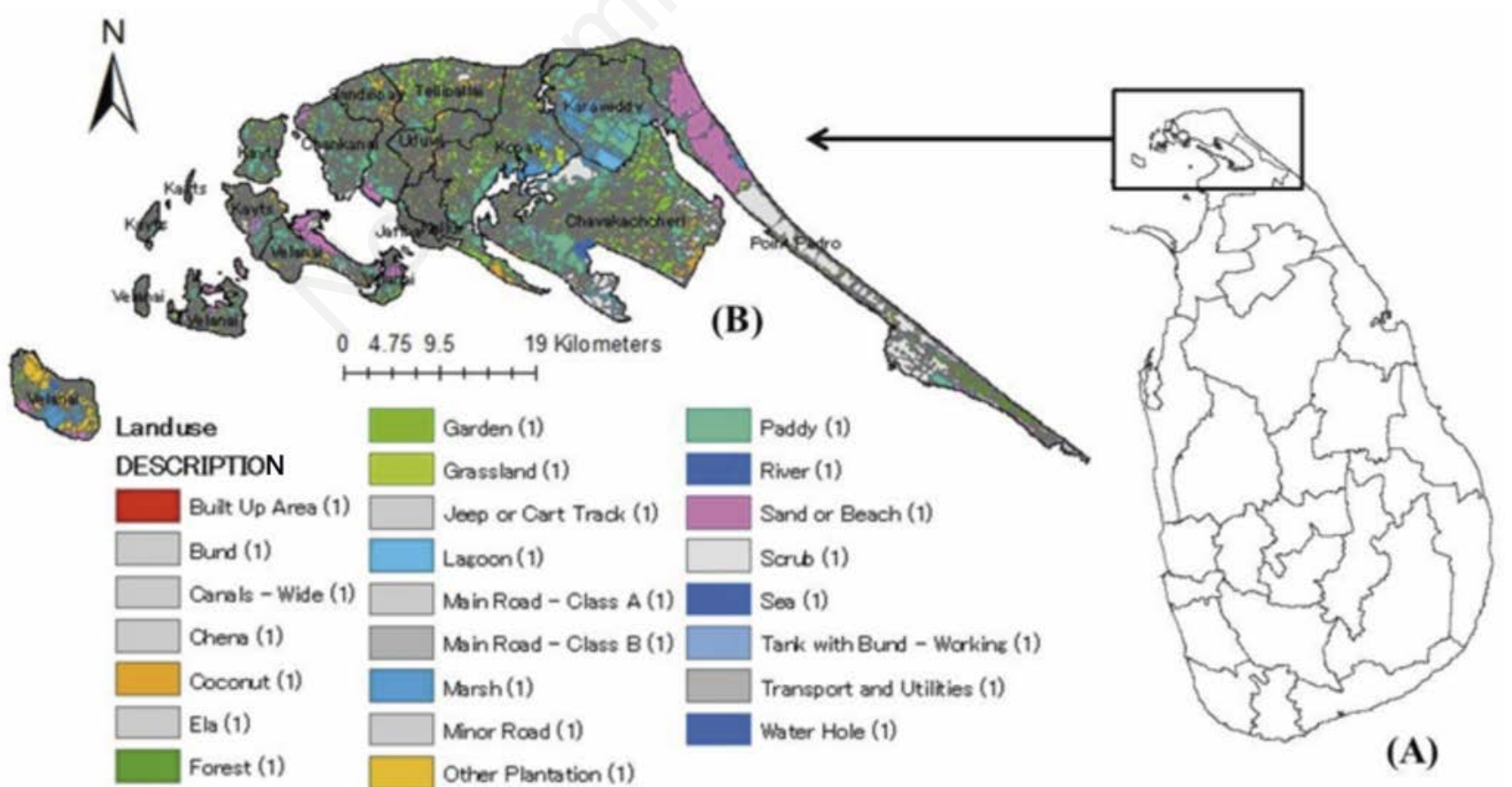

Figure 1. Digital land cover map of the northern region of Sri Lanka. Study area in Jaffna District (B) of Sri Lanka (A). 


\section{Ecological, socio-economic and demographic factors}

Operating under the Japan Aerospace Exploration Agency (JAXA), the Earth Observation Research Center (EORC) conducts Earth-observing satellite data acquisition, processing and providing satellite data (JAXA, 2014b). The Remote Sensing Technology Center of Japan (RESTEC) is commissioned by JAXA to administer all operations involving processing, analysis and distribution of data obtained from Earth-observation satellites (RESTEC, 2014). Earth-observing satellite data were processed to use as ecological factors in our study. The Global Satellite Mapping of Precipitation product, based on the combined MWIR algorithm with a plurality of satellites (JAXA, 2014b; RESTEC, 2014) ( h t t p ://sharaku.e or c.jaxa.jp/G S M a P/index.h t m; https://www.restec.or.jp/), was used for the monthly average rainfall data from January 2010 to December 2013 and the annual average rainfall data from 2007 to 2013. The JAXA Satellite Monitoring for Environmental Studies portal was used for the monthly average data for humidity and temperature from January 2010 to December 2013 and the annual average data for humidity and temperature from 2007 to 2013 (JAXA, 2014c) (http://kuroshio.eorc.jaxa.jp/JASMES/index.html). These data were processed into TIFF image files. Advanced Land Observation Satellite (ALOS)/the Advanced Visible and Near Infrared Radiometer type 2 (AVNIR-2) is a four band (visible and near-infrared) radiometer with a resolution of $10 \mathrm{~m}$, designed for observing land and coastal zones (JAXA, 2014a) (http://www.eorc.jaxa.jp/ALOS/ en/index.htm). The ALOS/AVNIR-2 dataset was used along with a method to detect and map the urbanisation ratio, i.e. the unmix method that isolates the contribution of a specific material within a heterogeneous (mixed) pixel (Applied Analysis Inc., 2003). For a given material, this method records pixel location and the fraction of material present in the pixel. We designated eight material pixel fraction classes that report subpixel detections in material pixel fraction increments of 0.20 ; e.g., pixels determined to have material pixel fractions of $20-29 \%$ belonged to class $0.20-0.29$, and pixels with material pixel fractions of 90-100\% belonged to class 0.90-1.00. A digital land cover map was used for land usage information, and these data were applied as ecological factors (Figure 1). Vector data on transportation, such as roads, railroads and airports, were obtained from the International Steering Committee for Global Mapping (ISCGM) Web site (ISCGM, 2014) (https:/www.iscgm.org/gmd/). Combining annual population data for the respective MOH division from 2007 to 2013 with the MOH division data for the area, we calculated the population density (Figure 2). These data were used as socio-economic and demographic factors.

\section{Spatial analysis}

ArcGIS version 10.2 (ESRI, 2013) was used for data pre-processing, spatial analysis and visualisation. The polygon layer produced by a geographic information system (GIS) using ArcGIS generated a view of the $12 \mathrm{MOH}$ divisions in northern Sri Lanka and the TIFF image data on rainfall, humidity and the temperature layer were overlaid. We extracted raster value from the TIFF image data according to polygonal templates and then assigned summaries of raster values to each polygon. The results were tabulated in Excel. Similarly, the values of the urbanisation raster within the polygons were summarised, with results also exported to Excel. We calculated the ratio of pixels with material pixel fractions of more than $50 \%$ to the $\mathrm{MOH}$ divisions. The polygon layer and the digital land cover map layer were overlaid. The land cover data within the polygons were summarised and tabulated in Excel. The vector data on the transportation network including roads, railroads and airports within the polygons were exported to Excel.

The table of polygon layer attributes was joined with the Excel tables containing data on the ecological, socio-economic and demographic factors. We also calculated the average value from a set of annual rain-

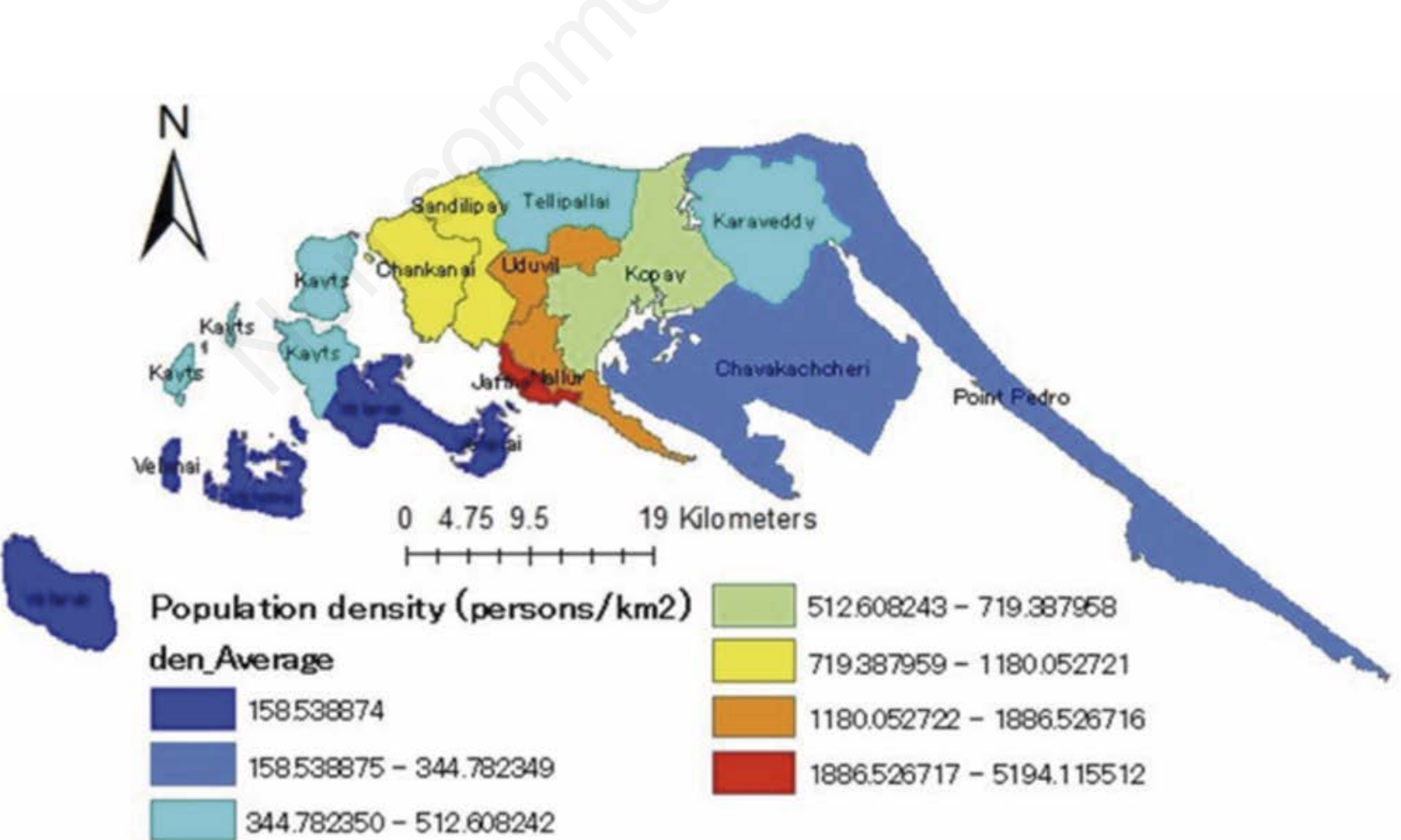

Figure 2. Population density at the medical health offices division level. 
fall, humidity, temperature and population density data at the MOH division level and used this information for spatial statistical analysis. In addition, the polygon layer that presented the $12 \mathrm{MOH}$ divisions was used to calculate the coordinates of the center of gravity of each polygon. This information was used for space-time clustering analysis.

\section{Temporal analysis}

To examine temporal patterns, we used data on monthly dengue cases, rainfall, humidity and temperature during the period from January 2010 through December 2013. We calculated the average monthly values from these data within the period to investigate the comprehensive trend and for the chi-square test. This test, available in Excel 2010 was used to test monthly differences in dengue cases, rainfall, humidity and temperature across the study period. The statistical significance was set at 0.05 .

\section{Spatial statistical analysis}

The chi-square test was used to test the spatial association between the ecological, socio-economic and demographic factors on the one hand and dengue outbreaks on the other. These factors were divided into two categories: i) above or below average for each factor or ii) the presence or absence of each factor. The threshold values for these categories were determined based on the average values for the factors from the results of the spatial analysis in GIS or based on the presence or absence of these factors from the results obtained with spatial analysis in GIS.

Regarding the ecological and urbanisation data, the threshold values were divided into two categories: above and below average. Land cover differed among $\mathrm{MOH}$ divisions, with some $\mathrm{MOH}$ divisions showing a total absence of a given land cover type. Regarding the land cover data, the threshold values were divided into two categories based on the presence or absence of each land cover.

Similarly, transportation types such as airport and railway differed among $\mathrm{MOH}$ divisions, with some MOH divisions showing a total absence of a given transportation system. Thus, for the airport and railway data, the threshold values were divided into two categories based on the presence or absence of each transportation type. For the road data, the threshold values were divided into two categories: above and below average, as were the population density data.

The categorised data for dengue cases and controls (i.e., population minus dengue cases) were used for the chi-square test in Excel 2010. The statistical significance was set at 0.05 .

\section{Spatio-temporal clustering analysis}

SaTScan, version 9.3 using the Kulldorf method of retrospective space-time analysis and a space-time permutation probability model was applied to identify geographic areas and the time period of potential clusters with high rates (Kulldorff, 2014). The scan statistics did scanning gradually across time and/or space to identify the number of observed and expected observations inside the window at each location. The scanning window was an interval (in time), a circle (in space), or a cylinder with a circular base (in space-time) to which window sizes were determined. Cylindrical windows were used in our study. The window with the maximum likelihood was the most likely cluster, and a P value was assigned to this cluster (Alemu et al., 2013). In this study, the monthly dengue cases from January 2010 to December 2013 in each MOH division and coordinate data from spatial analysis in GIS were used in the space-time permutation probability model. This approach was used to perform geographical surveillance of the disease to detect space-time disease clusters and see if they were statistically significant.

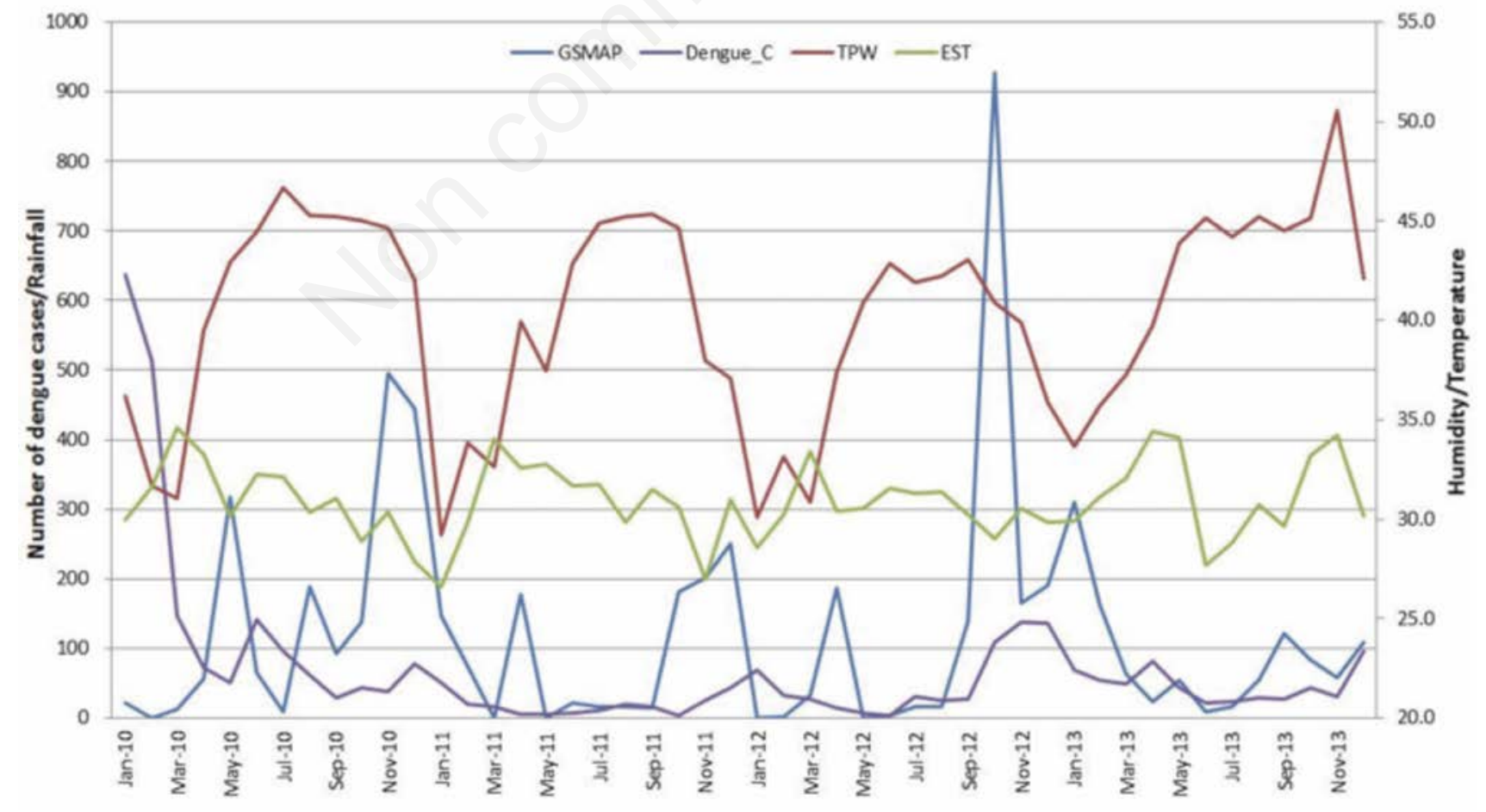

Figure 3. The temporal trends for the number of monthly dengue cases and ecological variables. The solid lines show monthly averages of dengue cases (purple), rainfall (blue), humidity (red), and temperature (green). 


\section{Results}

\section{Temporal trends for dengue and climate}

The temporal features of our investigation are shown in Figure 3. A total of 3,314 cases of dengue were reported in the northern region of Sri Lanka in the January 2010-December 2013 time series. The overall prevalence of dengue in the timeframe studied tended to be higher during the northeast monsoon (November to April). The epidemic pattern of dengue fluctuated with the prevailing climate. Humidity tends to rise in early January, remaining high during the dry season and then declining with the increase in rainfall in early September. These changes are accelerated at lower temperature. The distribution of monthly dengue cases indicated a strong seasonal pattern, and dengue cases tended to increase after exponential increases or decreases in rainfall. The chi-square test results supported these tendencies. We observed significant monthly differences in dengue cases $\left(\chi^{2}=498\right.$, $\mathrm{df}=11, \mathrm{P}=7.2781 \mathrm{E}-100)$ and rainfall $\left(\chi^{2}=930, \mathrm{df}=11, \mathrm{P}=2.0167 \mathrm{E}-192\right)$

Table 1. Results of the chi-square tests.

\begin{tabular}{|c|c|c|c|c|c|c|c|c|c|c|c|c|c|c|}
\hline & Jan & Feb & Mar & Apr & May & Jun & Jul & Aug & Sep & Oct & Nov & Dec & Total & $\mathbf{P}$ \\
\hline $\begin{array}{c}\text { Dengue cases } \\
\text { Ho } \\
\mathrm{He} \\
\chi^{2}\end{array}$ & $\begin{array}{c}206 \\
69 \\
273\end{array}$ & $\begin{array}{c}155 \\
69 \\
108\end{array}$ & $\begin{array}{c}60 \\
69 \\
1\end{array}$ & $\begin{array}{c}44 \\
69 \\
9\end{array}$ & $\begin{array}{l}26 \\
69 \\
27\end{array}$ & $\begin{array}{l}43 \\
69 \\
10\end{array}$ & $\begin{array}{l}40 \\
69 \\
12\end{array}$ & $\begin{array}{l}34 \\
69 \\
18\end{array}$ & $\begin{array}{l}25 \\
69 \\
28\end{array}$ & $\begin{array}{c}50 \\
69 \\
5\end{array}$ & $\begin{array}{c}58 \\
69 \\
2\end{array}$ & $\begin{array}{c}88 \\
69 \\
5\end{array}$ & $\begin{array}{l}829 \\
829 \\
498\end{array}$ & 7.2781 E-100 \\
\hline $\begin{array}{c}\text { Rainfall } \\
\text { Ho } \\
\text { He } \\
\chi^{2}\end{array}$ & $\begin{array}{c}120 \\
119 \\
0\end{array}$ & $\begin{array}{c}60 \\
119 \\
29\end{array}$ & $\begin{array}{c}27 \\
119 \\
71\end{array}$ & $\begin{array}{c}111 \\
119 \\
0\end{array}$ & $\begin{array}{c}93 \\
119 \\
5\end{array}$ & $\begin{array}{c}25 \\
119 \\
74\end{array}$ & $\begin{array}{c}14 \\
119 \\
92\end{array}$ & $\begin{array}{c}69 \\
119 \\
21\end{array}$ & $\begin{array}{c}92 \\
119 \\
6\end{array}$ & $\begin{array}{l}332 \\
119 \\
386\end{array}$ & $\begin{array}{l}230 \\
119 \\
105\end{array}$ & $\begin{array}{l}248 \\
119 \\
142\end{array}$ & $\begin{array}{c}1422 \\
1422 \\
930\end{array}$ & 2.0167 E-192 \\
\hline $\begin{array}{c}\text { Humidity } \\
\text { Ho } \\
\mathrm{He} \\
\chi^{2}\end{array}$ & $\begin{array}{c}32 \\
40 \\
2\end{array}$ & $\begin{array}{c}34 \\
40 \\
1\end{array}$ & $\begin{array}{c}33 \\
40 \\
1\end{array}$ & $\begin{array}{c}39 \\
40 \\
0\end{array}$ & $\begin{array}{c}41 \\
40 \\
0\end{array}$ & $\begin{array}{c}44 \\
40 \\
0\end{array}$ & $\begin{array}{c}44 \\
40 \\
0\end{array}$ & $\begin{array}{c}44 \\
40 \\
0\end{array}$ & $\begin{array}{c} \\
45 \\
40 \\
0\end{array}$ & $\begin{array}{c}44 \\
40 \\
0\end{array}$ & $\begin{array}{c}43 \\
40 \\
0\end{array}$ & $\begin{array}{c}39 \\
40 \\
0\end{array}$ & $\begin{array}{c}483 \\
483 \\
6\end{array}$ & 0.85 \\
\hline $\begin{array}{c}\text { Temperature } \\
\mathrm{Ho} \\
\mathrm{He} \\
\chi^{2}\end{array}$ & $\begin{array}{c}29 \\
31 \\
0\end{array}$ & $\begin{array}{c}31 \\
31 \\
0\end{array}$ & $\begin{array}{c}34 \\
31 \\
0\end{array}$ & $\begin{array}{c}33 \\
31 \\
0\end{array}$ & $\begin{array}{c}32 \\
31 \\
0\end{array}$ & $\begin{array}{c}31 \\
31 \\
0\end{array}$ & $\begin{array}{c}31 \\
31 \\
0\end{array}$ & $\begin{array}{c}31 \\
31 \\
0\end{array}$ & $\begin{array}{c}31 \\
31 \\
0\end{array}$ & $\begin{array}{c}30 \\
31 \\
0\end{array}$ & $\begin{array}{c}31 \\
31 \\
0\end{array}$ & $\begin{array}{c}30 \\
31 \\
0\end{array}$ & $\begin{array}{c}371 \\
371 \\
1\end{array}$ & 1.00 \\
\hline
\end{tabular}

Ho, observed values; He, expected values. Observed values represent the monthly average of dengue case, rainfall, humidity and temperature for a time period spanning the past three years (2010 to 2013).

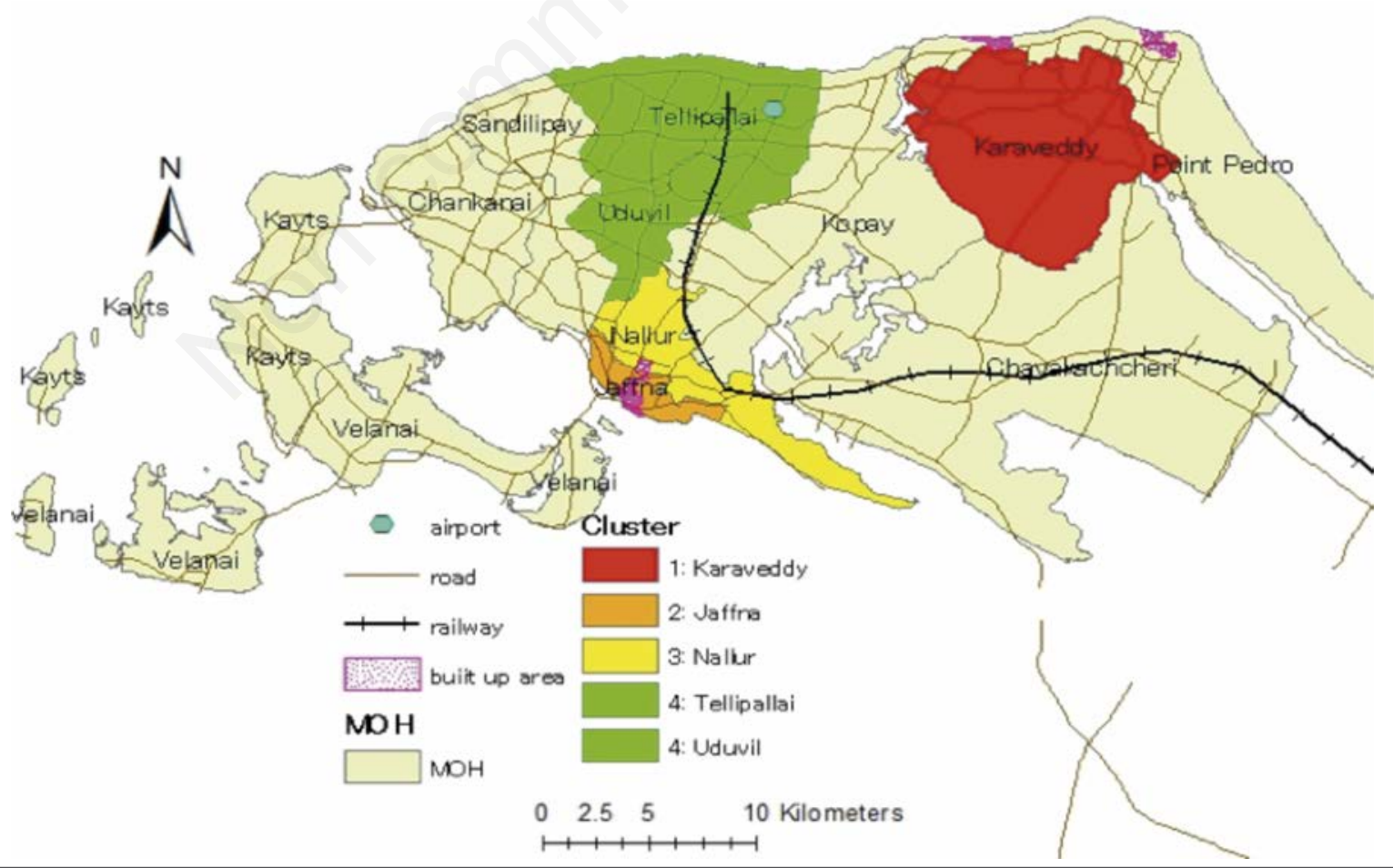

Figure 4. Spatial distribution of statistically significant high-rate dengue clusters at the medical health offices division level in northern Sri Lanka, January 2010-December 2013. Colour identification of the clusters was ordered based on the value of the test retrospective space-time analysis. 
while humidity $\left(\chi^{2}=6, \mathrm{df}=11, \mathrm{P}=0.85\right)$ and temperature $\left(\chi^{2}=1, \mathrm{df}=11\right.$, $\mathrm{P}=1.00$ ) were not significant (Table 1).

\section{Spatial distribution of ecological, socio-economic and demographic factors associated with dengue out- breaks}

The results of spatial statistical analysis are shown in Table 2. The spatial statistical analysis revealed that dengue outbreaks were significantly associated with ecological, socio-economic and demographic factors. Significantly more dengue cases were observed in the Chankanai, Chavakachcheri, Jaffna, Karaveddy, Nallur, Point Pedro, Sandilipay, and Tellipallai MOH divisions (66.7\%) with average annual rainfall of $>1353 \mathrm{~mm}$ compared to those with an average annual rainfall of $<1353 \mathrm{~mm}\left(\chi^{2}=112.8 ; \mathrm{P}<0.01\right)$. Correspondingly, we also observed significantly more dengue cases in the Chavakachcheri, Jaffna, Karaveddy, Kopay, Point Pedro, Sandilipay, Tellipallai, and Uduvil MOH divisions (66.7\%) with average an annual humidity of $>39.62 \mathrm{~mm}$ compared to those with an average annual humidity of $<39.62 \mathrm{~mm}\left(\chi^{2}=55.6 ; \mathrm{P}<0.01\right)$. Moreover, significantly more dengue cases occurred in the Chankanai, Chavakachcheri, Karaveddy, Kopay, Sandilipay, Tellipallai, and Uduvil MOH divisions (58.3\%) with an average annual temperature of $>31.2^{\circ} \mathrm{C}$ compared to those divisions with an average annual temperature of $<31.2^{\circ} \mathrm{C}\left(\chi^{2}=104.7 ; \mathrm{P}<0.01\right)$.

Significantly more dengue cases were observed in the Chavakachcheri, Jaffna, Karaveddy, Kayts, Point Pedro, and Velanai $\mathrm{MOH}$ divisions (50.0\%) that had a ratio of $>18 \%$ to $\mathrm{MOH}$ division area compared to those divisions with a ratio of $<18 \%$ to MOH division area $\left(\chi^{2}=40.7 ; \mathrm{P}<0.01\right)$. Dengue occurrence was also significantly associated with the presence or absence of built-up area, considered to represent urbanisation $\left(\chi^{2}=264.7 ; \mathrm{P}<0.01\right)$. The presence of built-up area in the Karaveddy, Jaffna, Nallur, and Point Pedro MOH divisions (33.3\%) significantly influenced dengue occurrence.

Dengue occurrence was also significantly associated with the presence or absence of a railways $\left(\chi^{2}=63.5 ; \mathrm{P}<0.01\right)$, although the presence or absence of an airport did not have a significant influence. The presence of a railway in the Chavakachcheri, Kopay, Nallur, Tellipallai, and Uduvil MOH divisions (41.7\%) significantly influenced dengue occurrence. We also found significantly more dengue cases in the Chankanai, Kopay, Sandilipay, Tellipallai, and Velanai MOH divisions (41.7\%) with $>25$ roads compared to those with $<25$ roads $\left(\chi^{2}=96.4\right.$; $\mathrm{P}<0.01)$. In addition, significantly more dengue cases were identified in the Jaffna, Nallur, Uduvil, and Sandilipay MOH divisions (33.3\%) with a population density of $>1150$ compared to those divisions with a population density of $<1150\left(\chi^{2}=347.2 ; \mathrm{P}<0.01\right)$.

Table 2. Results of spatial statistical analysis.

\begin{tabular}{|c|c|c|c|c|c|}
\hline Factors & & N (\%) & $P\left(x^{2}\right)$ & OR & $95 \%$ CI \\
\hline \multirow[t]{2}{*}{ Rainfall (mm) } & $>1353$ & $8(66.7)$ & \multirow[t]{2}{*}{$<0.01(112.8)$} & \multirow[t]{2}{*}{1.536} & \multirow[t]{2}{*}{$1.418-1.663$} \\
\hline & $<1353$ & $4(33.3)$ & & & \\
\hline Humidity (mm) & $\begin{array}{l}>39.62 \\
<39.62\end{array}$ & $\begin{array}{l}8(66.7) \\
4(33.3)\end{array}$ & $<0.01(55.6)$ & 1.35 & $1.247-1.461$ \\
\hline \multirow[t]{2}{*}{ Temperature $\left({ }^{\circ} \mathrm{C}\right)$} & $>31.2$ & $7(58.3)$ & \multirow[t]{2}{*}{$<0.01(104.7)$} & \multirow[t]{2}{*}{0.715} & \multirow[t]{2}{*}{$0.67-0.762$} \\
\hline & $<31.2$ & $5(41.7)$ & & & \\
\hline Urbanisation (\%) & $\begin{array}{l}>18 \\
<18\end{array}$ & $\begin{array}{l}6(50.0) \\
6(50.0)\end{array}$ & $<0.01(40.7)$ & 1.233 & $1.156-1.315$ \\
\hline \multirow[t]{2}{*}{ Built-up area } & Presence & $4(33.3)$ & \multirow[t]{2}{*}{$<0.01(264.7)$} & \multirow[t]{2}{*}{1.697} & \multirow[t]{2}{*}{$1.591-1.81$} \\
\hline & Absence & $8(66.7)$ & & & \\
\hline Railway & $\begin{array}{c}\text { Presence } \\
\text { Absence }\end{array}$ & $\begin{array}{l}5(41.7) \\
7(58.3)\end{array}$ & $<0.01(63.5)$ & 0.767 & $0.719-0.819$ \\
\hline \multirow[t]{2}{*}{ Airport } & Presence & $1(8.3)$ & \multirow[t]{2}{*}{$(1.7)$} & \multirow[t]{2}{*}{1.099} & \multirow[t]{2}{*}{$0.954-1.268$} \\
\hline & Absence & 11 (91.7) & & & \\
\hline Road (\%) & $\begin{array}{l}>25 \\
<25\end{array}$ & $\begin{array}{l}5(41.7) \\
7(58.3)\end{array}$ & $<0.01(96.4)$ & 0.706 & $0.658-0.757$ \\
\hline \multirow[t]{2}{*}{ Population density } & $>1150$ & $4(33.3)$ & \multirow[t]{2}{*}{$<0.01(347.2)$} & \multirow[t]{2}{*}{1.83} & \multirow[t]{2}{*}{$1.716-1.952$} \\
\hline & $<1150$ & $8(66.7)$ & & & \\
\hline
\end{tabular}

$\mathrm{OR}$, odds ratio; $\mathrm{Cl}$, confidence interval.

Table 3. Significantly high rates of spatial clusters of dengue in the northern region of Sri Lanka between January 2010 and December 2013.

\begin{tabular}{lcccccc} 
Location & \multicolumn{1}{c}{ Time frame } & Cases (n) & Expected cases (n) & Observed cases (n) & Test statistics & P \\
Karaveddy & $2010 / 06 / 01$ to 2010/06/30 & 85 & 13.87 & 6.13 & 83.74 & $<0.001$ \\
Jaffna & $2010 / 09 / 01$ to 2011/01/31 & 172 & 60.94 & 2.82 & 69.33 & $<0.001$ \\
\hline Nallur & $2012 / 10 / 01$ to 2012/11/30 & 101 & 27.54 & 3.67 & 58.62 & $<0.001$ \\
Tellipallai and Uduvil & $2011 / 12 / 01$ to 2012/03/31 & 54 & 21.9 & 2.47 & 16.79 & $<0.001$ \\
\hline
\end{tabular}




\section{Space-time clustering characteristics of dengue out- breaks based on ecological, socio-economic and demographic factors}

Space-time clustering analysis by SaTScan indicated four space-time clusters with significantly high rates of dengue cases $(\mathrm{P}<0.001)$ (Table 3 ). Figure 4 gives the map with the layer of four space-time clusters obtained from space-time clustering analysis, with the digital land cover map and the digital transportation network map layers visualised.

The combination of space-time clustering analysis with the results of temporal and spatial statistical analysis indicated that increases in the number of combinations of ecological, socio-economic and demographic factors that were either present or above average contributed to significantly high rates of space-time dengue clusters. The most likely space-time cluster was identified in the Karaveddy MOH division from 1 June 2010 to 30 June 2010. This division is urbanised land area with relatively high rainfall, high humidity, and high temperature. The second space-time cluster was identified in the Jaffna MOH division from 1 September 2010 to 31 January 2011. This division is urbanised land area with relatively high rainfall, high humidity, and high population density. The third space-time cluster was identified in the Nallur MOH division from 1 October 2012 to 30 November 2012. Railways and urbanised land characterise this division, which has relatively high rainfall and a high population density. The fourth space-time clusters were identified in the Tellipallai and Uduvil $\mathrm{MOH}$ divisions from 1 December 2011 to 31 March 2012. Both divisions are traversed by railways and have relatively high humidity and high temperature; other characteristics of each division are relatively high rainfall, high road and high population density.

\section{Discussion}

Our research and other Southeast Asian studies carried out by Ling et al. (2014) in Malaysia and Dhewantara et al. (2015) in Indonesia confirm that dengue cases tend to cluster showing both a spatial and a temporal epidemiological component. The findings referred to highlight the importance of detailed geographical analysis of disease cases in heterogeneous environments with a focus on clustered populations at different spatial and temporal scales. To our knowledge, this is the first study to investigate the impact of downloaded RS data on ecological factors together with socio-economic and demographic factors (i.e., urbanisation, transportation and population density) on space-time dengue clusters. Dengue transmission within Sri Lanka is spatially heterogeneous. Further research must focus on the whole island to improve the accuracy of spatial and temporal models while using big data and open data.

From a temporal point of view, the result of space-time clustering analysis corresponds to that for temporal analysis in that number of dengue cases tended to increase after exponential increases or decreases in rainfall and when the maximum monthly rainfall reached $200 \mathrm{~mm}$. The most likely space-time cluster was detected in the Karaveddy MOH division from 1 June 2010 to 30 June 2010. It supported unusually large epidemics in 2004 and 2009 with peak transmission occurring in June following the southwest monsoon (Tam et al., 2013). From a spatial perspective, the space-time clustering analysis results indicated that increases in the number of combinations of ecological, socio-economic and demographic factors (i.e., rainfall, humidity, temperature, urbanisation, railways, roads and population density) that were present or above average contributed to significantly high rates of space-time dengue clusters as well as a high risk of dengue transmission.

The temporal, spatial statistical and space-time clustering analyses implemented in this study identified dengue space-time clusters with a higher dengue burden and greater risks for dengue transmission and identified the geographic areas and time periods associated with highest dengue risk at the MOH division level. These clusters and surrounding areas should be targeted for dengue prevention and control interventions.

\section{Conclusions}

The presently observed temporal association underlines the fact that rainfall, humidity, and temperature can strengthen time prediction models. The spatial association found in our study highlights the fact that built-up area and urbanisation (ecological factors), transportation (socio-economic and demographic factor) and higher population density (socio-economic and demographic factor) can also strengthen spatial prediction models. A spatial-temporal association that consolidates the two kinds of associations into one can ensure a more stable model for spatial-temporal forecasting. Furthermore, an integrated spatialtemporal prediction model at a smaller level using ecological, socioeconomic and demographic factors could lead to substantial improvements in the control and prevention of dengue by allocating the right resources to the appropriate places at the right time with the technology of cloud GIS, i.e. the combination of running GIS software and services on the web using the cloud infrastructure for storing data (ESRI, 2015).

\section{References}

Alemu K, Worku A, Berhane Y, 2013. Malaria infection has spatial, temporal, and spatiotemporal heterogeneity in unstable malaria transmission areas in northwest Ethiopia. PLoS One 8:e79966.

Applied Analysis Inc., 2003. IMAGINE Subpixel classifier user's guide. Applied Analysis Inc., Billerica, MA, USA.

Banu S, Hu W, Hurst C, Guo Y, Islam MZ, Tong S, 2012. Space-time clusters of dengue fever in Bangladesh. Trop Med Int Health 17:108691.

Canyon DV, Hii JL, Müller R, 1999. Adaptation of Aedes aegypti (Diptera: Culicidae) oviposition behavior in response to humidity and diet. J Insect Physiol 45:959-64.

Dempsey AF, Cowan AE, Broder KR, Kretsinger K, Stokley S, Clark SJ, 2009. Diagnosis and testing practices for adolescent pertussis among a national sample of primary care physicians. Prev Med 48:500-4.

Dhewantara PW, Ruliansyah A, Fuadiyah MEA, Astuti EP, Widawati M, 2015. Space-time scan statistic of dengue incidence 2007-2013 in Cimahi city, West Java. Geospat Health 10:373 (in press).

ESRI, 2013. ArcGIS 10.2 desktop. Environmental Systems Research Institute, Redlands, CA, USA.

ESRI, 2015. Topics in Cloud GIS. Available from: http://www.esri. com/products/arcgis-capabilities/cloud-gis

Gubler DJ, 1997. Dengue and dengue hemorrhagic fever: its history and resurgence as a global public health problem. In: Gubler DJ, Kuno G, eds. Dengue and dengue hemorrhagic fever. CAB International, Wallingford, UK, pp 1-22. 
Gubler DJ, 1998. Dengue and dengue hemorrhagic fever. Clin Microbiol Rev 11:480-96.

Gubler DJ, 2011. Dengue, urbanization and globalization: the unholy trinity of the $21^{\text {st }}$ century. Trop Med Health 39:3-11.

ISCGM, 2014. International Steering Committee for Global Mapping. Available from: https://www.iscgm.org/gmd/

JAXA, 2014a. Advanced Land Observation Satellite (ALOS). Available from: http://www.eorc.jaxa.jp/ALOS/en/index.htm

JAXA, 2014b. JAXA Global Rainfall Watch. Available from: http://sharaku.eorc.jaxa.jp/GSMaP/index.htm

JAXA, 2014c. JAXA Satellite Monitoring for Environmental Studies (JASMES). Available from: http://kuroshio.eorc.jaxa.jp/ JASMES/index.html

Jeefoo P, Tripathi NK, Souris M, 2011. Spatio-temporal diffusion pattern and hotspot detection of dengue in Chachoengsao Province, Thailand. Int J Environ Res Public Health 8:51-74.

Kanakaratne N, Wahala WM, Messer WB, Tissera HA, Shahani A, Abeysinghe N, de-Silva AM, Gunasekera M, 2009. Severe dengue epidemics in Sri Lanka, 2003-2006. Emerg Infect Dis 15:192-9.

Kulldorff M, 2014. SaTScan ${ }^{\mathrm{TM}}$ user guide for version 9.3. Available from: http://www.satscan.org/

Lian CW, Seng CM, Chai WY, 2006. Spatial, environmental and entomological risk factor analysis on a rural dengue outbreak in Lundu District in Sarawak, Malaysia. Trop Biomed 23:85-96.

Ling CY, Gruebner 0, Krämer A, Lakes T, 2014. Spatio-temporal patterns of dengue in Malaysia: combining address and sub-district level. Geospatial Health 9:131-40.

Ooi EE, Gubler DJ, 2008. Dengue in Southeast Asia: epidemiological characteristics and strategic challenges in disease prevention. Cad
Saude Publica 25:115-24.

RESTEC, 2014. Global Satellite Mapping of Precipitation (GSMaP). Available from: https://www.restec.or.jp/

Rodhain F, Rosen L, 1997. Mosquito vectors and dengue virus-vector relationships. In: Gubler DJ, Kuno G, eds. Dengue and dengue hemorrhagic fever. CAB International, Wallingford, UK, pp 45-60.

Sharma KD, Mahabir RS, Curtin KM, Sutherland JM, Agard JB, Chadee DD, 2014. Exploratory space-time analysis of dengue incidence in Trinidad: a retrospective study using travel hubs as dispersal points, 1998-2004. Parasite Vector 7:1-11.

Solano R, Gómez-Barroso D, Simón F, Lafuente S, Simón P, Rius C, Gorrindo $\mathrm{P}$, Toledo D, Caylà JA, 2014. Retrospective space-time cluster analysis of whooping cough, re-emergence in Barcelona, Spain, 2000-2011. Geospat Health 8:455-61.

Tam CC, Tissera H, de Silva AM, De Silva AD, Margolis HS, Amarasinge A, 2013. Estimates of dengue force of infection in children in Colombo, Sri Lanka. PLoS Neglect Trop Dis 7:1-7.

Tran HP, Adams J, Jeffery JA, Nguyen YT, Vu NS, Kutcher SC, Kay BH, Ryan PA, 2010. Householder perspectives and preferences on water storage and use, with references to dengue, in the Mekong Delta, southern Vietnam. Hum Res Dev 2:136-42.

WHO, 2011. Comprehensive guidelines for prevention and control of dengue and dengue haemorrhagic fever. Revised and expanded edition, New Delhi. Available from: http:/www.searo.who.int/entity/vector_borne_tropical_diseases/documents/SEAROTPS60/en/in dex.html

WHO, 2012. Dengue and severe dengue. Available from: http://www.who.int/mediacentre/factsheets/fs117/en/ 